\section{Release from proactive inhibition as a function of pleasantness of verbal materials*}

\author{
J. PETER KINCAID and FULTON COOPER \\ Georgia Southern College, Statesboro, Ga., 30458
}

In a Peterson and Peterson type of short-term memory experiment, proactive inhibition has been found to build up rather rapidly but is overcome if a shift to a new type of material occurs. This experiment tested whether release from proactive inhibition may occur as a result of changing from unpleasant words to pleasant words, and vice versa. Two hundred introductory psychology students served as Ss. In all instances, the experimental groups demonstrated improved recall on the critical trial as opposed to the control groups, which showed no improvement on the critical trial. The results of this experiment are interpreted as indicating that pleasant and unpleasant words are encoded or perhaps stored in memory differently.

Investigation into the manner of encoding of verbal materials has become of some interest in the last decade or so. Wickens (1970) postulates that words are encoded within a number of aspects, attributes, or psychological dimensions.

One of the chief methods of investigation into the encoding by category concept is the study of proactive inhibition, or in other words, the presentation of verbal materials of similar category to a $\mathbf{S}$ over a number of trials. When maximum interference has built up and recall has reached a rather constant level, materials from another category are presented to demonstrate release from proactive inhibition if the materials are encoded differently.

The buildup of proactive inhibition over a series of trials of similar materials has been demonstrated repeatedly over the last 10 years (Keppel \& Underwood, 1962; Wickens, Born, \& Allen, 1963; Loess, 1964). It has been found that a change of category for materials on the fourth or fifth trial effects a release from practive inhibition (PI) or a recovery of recall for the subsequent item from a different category. Wickens, Born, \& Allen (1963) employed consonants (CCCs) presented for three trials, changing to numbers (NNNs) on the fourth and critical trial. A release from proactive inhibition was noted, and it was found that the maximum interference occurred after approximately four trials of similar-category materials.

This type of study lends itself to the investigation of organization of memory, according to the model of memory as being composed of "pigeon holes" or "cubicles." This theory

* Based on a thesis submitted by Cooper in partial fulfillment of the MA degree at Georgia Southern College. Kincaid acted as thesis director. presentation of trials.

SUBJECTS

The Ss used in this experiment were introductory psychology students from Georgia Southern College. Two hundred Ss were used, 100 for the two control groups and 100 for the two experimental groups, or $50 \mathrm{Ss}$ for each of the four groups used.

\section{APPARATUS AND}

\section{VERBAL MATERIALS}

The equipment consisted of an Argus 541 slide projector for presentation of the slides, a Gerbrands tape timer for control of the presentation times for each slide, and a Lafayette electric metronome to pace Ss in naming the colors on the interpolating task, the Stroop slide The Stroop slide was used as an interpolating task between the presentation of the three words to be recalled and the actual recall period itself. The Stroop slide inhibits rehearsal of the triads by having $\mathrm{Ss}$ name the colors of words which are actually written in a different color Previous experience with the Stroop slide (Kincaid \& Wickens, 1970) indicated that it is a good way to control rehearsal of the verbal material. The experimental slides consisted of 10 slides containing three pleasant words each and 10 slides containing three unpleasant words each. The list of pleasant and unpleasant words used in the experiment were taken from a list compiled by Young (1937) in which he required 555 introductory psychology students to list words which were pleasant and unpleasant to them. The students then checked the several words which were most pleasant and unpleasant. From this list, Young compiled 1,979 pleasant words and 1,801 unpleasant words. Eriksen, Azuma, \& Hicks (1959) chose the 60 most frequently listed words from Young's list, 30 pleasant and 30 unpleasant, to judge the emotional quality of stimuli presented subliminally to a $\mathrm{S}$. The list of words used in the present experiment is the complete list of 60 words used by Eriksen et al. The assignment of the three words to any particular slide was done by random selection; however, adjustments were made if the words happened to be of the same length, the same number of syllables, or began with the same letter. The selection of the triads to be used with each $S$ was at random also. A list was constructed prior to the experiment, and the slides were changed after each $S$, according to the listing.

\section{PROCEDURE}

The basic Peterson \& Peterson (1959) format was used for presentation of the word triads, i.e., a verbal triad had to be remembered 


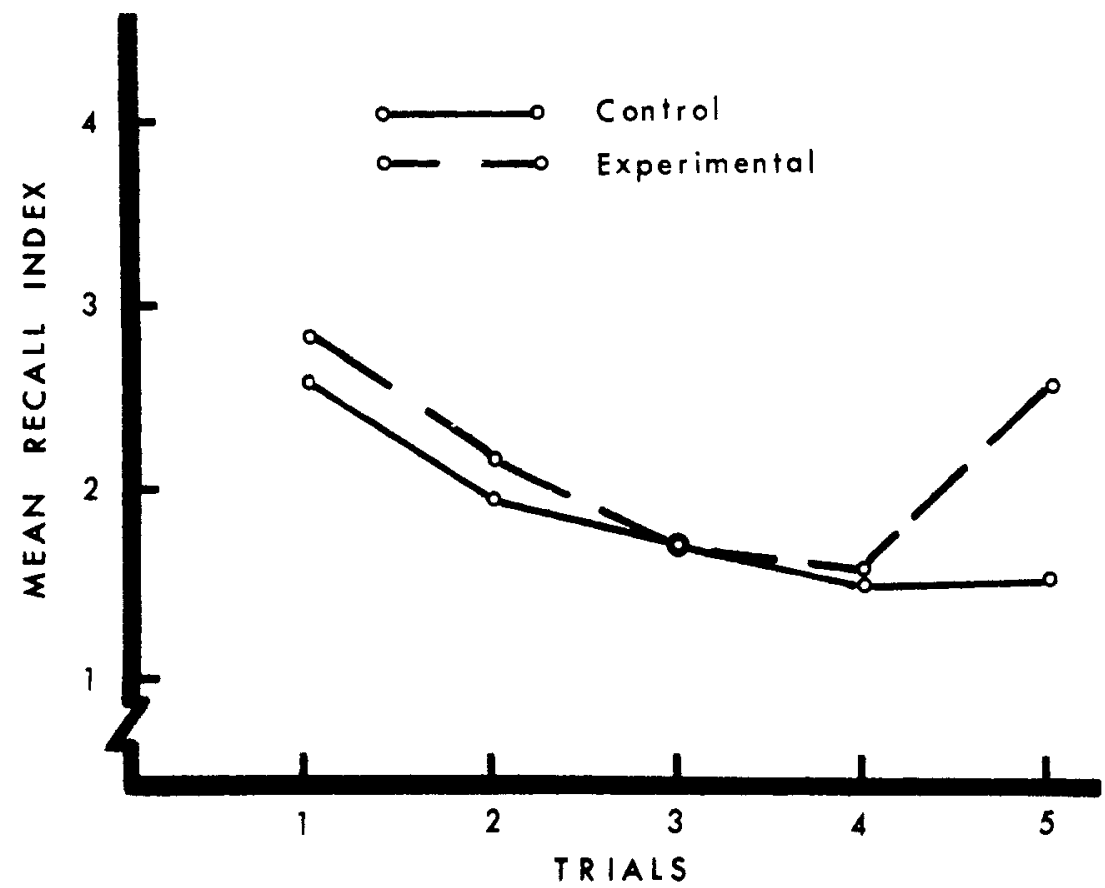

Fig. 1. Mean recall scores for the two experimental groups combined and the two control groups combined. Trial 5 was the critical trial, and category was switched for the experimental groups.

during the duration of a rehearsal controlling activity. Four trials were used for buildup of proactive inhibition for the experimental groups, with the fifth trial being the critical or change of category trial. The control groups received five trials consisting of slides from a homogeneous category throughout all five trials. The retention interval, or the period covered by the Stroop slide, was $15 \mathrm{sec}$ for all groups. The colors in the slide were named by $S$ to the beat of the metronome at 1 beat/sec.

The Ss entered the experimental area and sat about $6 \mathrm{ft}$ from the screen, on which the words were to be projected. Instructions were read to $S$. The tape timer was then started, and $S$ 's responses were recorded by $\mathrm{E}$ on a prepared form. When finished, $\mathrm{S}$ was instructed not to discuss what had transpired with classmates who were to participate later. Ss were assigned to the four groups (two experimental and two control groups) as they appeared.

A single trial consisted of four phases. An asterisk was presented for 2 sec as a get-ready cue, the three words then appeared for $3 \mathrm{sec}$, followed by the Stroop slide for $15 \mathrm{sec}$, and culminating with a ques ion mark for $10 \mathrm{sec}$, at which time the $S$ was to recall aloud to $E$ the three words seen before the Stroop slide. Each $S$ received five such trials. RESULTS

Each $\mathrm{S}$ was scored by giving 1 point for each correctly recalled word and 1 extra point if they were in the correct order. This was the same scoring technique used by Kincaid \& Wickens (1970). The mean recall scores are shown in Fig. 1 for the combined control and experimental groups. It is evident from inspection of Fig. 1 that recall declines over the first four trials, or in other words that proactive inhibition builds up. It is also evident that recall is greater on the test trial (Trial 5) if the category is switched, or in other words if release from proactive inhibition occurs. These impressions are completely supported by two analyses of variance, one employed on the data of the first four trials and the other on the fifth and critical trial data.

The first analysis of variance was employed on the first four trials to assess the buildup of proactive inhibition and to test for differences between the pleasant and unpleasant slides. There was a significant difference between the pleasant and unpleasant word groups for the first four trials at the .01 level, $F(1,198)=$ 5.41. The pleasant word triads had a slightly higher recall score than the unpleasant slides. The mean recall index for all Ss on trials for the two groups were: pleasant slides, 2.83 , $2.09,1.85$, and 1.82 ; unpleasant slides, $2.63,2.10,1.63$, and 1.32 , over the four trials. There was a highly significant difference noted between the first, second, third, and fourth trials for both the pleasant and unpleasant groups of slides, $F(3,594)=$ $42.44, \mathrm{p}<.01$.
The second analysis of variance was executed on the fifth trial data for the four groups, and the main effect (groups) was found to be significant at the .05 level, $F(3,196)=12.29$. A Tukey's HSD multiple comparison test was performed on the four means for the rour groups (Kirk, 1968), and a significant difference was noted between both control groups when compared with each experimental group, and vice versa. These differences were all significant at the .05 level. There was no significant difference between the two control groups nor between the two experimental groups when compared with each other.

\section{DISCUSSION}

The results of the experiment definitely supported the hypothesis that a release from proactive inhibition would occur as a function of the change from pleasant to unpleasant words and from unpleasant to pleasant words on the fifth and critical trial. This result basically supports the research findings of Wickens \& Clark (1968), in which they found that changing from one end of the Osgood differential dimensions to the other end on the critical trial brought about release from PI. The category of "pleasantness" is similar to the evaluative scale of the Osgood semantic differential. The increase of recall on the fifth trial in this experiment is interpreted as evidence of a release from proactive inhibition which had built up on the first four trials.

For this experiment, the percentage of release from proactive inhibition for the combined experimental groups was $92 \%$. The recovery for the two experimental groups separately was, for pleasant slides, $94 \%$; for unpleasant slides it was $90 \%$. These values were computed by employing the procedure used by Wickens (1970) in which the amount of decline from Trial 1 to the shift trial was obtained for the control group. This was then divided into the difference between the control and experimental group on the critical trial to give a percentage of recovery. The minimal value required for significance at the .05 level on a two-tailed test is typically about $25 \%$ recovery. Wickens \& Clark (1968) found approximately $51 \%$ recovery on the evaluative scale of the Osgood differential, which is similar to the materials used in this study. The $92 \%$ release found in this study is attributed to the extreme difference between the pleasant and urnleasant words used, this difference belisg more extreme than that employed in the earlier study (Wickens \& Clark, 1968).

The question of interference or decay as the major contributing factor 
in the lessening of recall has been of some interest in this type of research. It is generally accepted in proactive inhibition studies that interference builds up with each successive trial of four trials (Keppel \& Underwood, 1962). The almost complete recovery of recall on the critical trial for the experimental groups indicates that the different categories of materials on that trial had no interference buildup from the previous trials.

In summary, this study is additional confirmation of the release from proactive inhibition phenomenon reviewed so thoroughly by Wickens (1970). It demonstrates that pleasant words are encoded or perhaps stored differently from unpleasant words.
REFERENCES

ERIKSEN, C W., AZUMA, H., \& HICKS R. Verbal discrimination of pleasant and unpleasant stimuli prior to specific identification. Journal of Abnormal \& Social Psychology, 1959, 59, 114-119.

KEPPEL G. \& UNDERWOOD, B. J Proactive inhibition in short-term retention of single items. Journal of Verbal Learning \& Verbal Behavior, 1962, 1, 153-161.

KINCAID, J. P. \& WICKENS, D. D. Temporal gradient of release from proactive inhibition. Journal of Experimental Psychology, 1970, 86, 313-316.

KIRK, R. E. Experimental design: Procedures for the behavioral sciences. Belmont, Calif: Brooks/Cole, 1968.

LOESS, H. Proactive inhibition in short-term memory. Journal of Verbal Learning \& Verbal Behavior, 1964, 3, 362-368.

OSGOOD, C. E., SUCI, G. J., \&
TANNENBAUM, P. H. The measurement of meaning. Urbana: University of llinois Press, 1957.

PETERSON, L. R., \& PETERSON, M. J. Short-term retention of individual verbal items. Journal of Experimental Psychology, 1959, 58, 193-198.

WICKENS, D. D. Encoding categories in short-term memory. Psychological Review, 1970, 77, 1-15.

WICKENS, D. D. BORN, D. G. \& ALLEN C. K. Proactive inhibition and item similarity in short-term memory. Journal of Verbal Learning \& Verbal Behavior, $1963,2,440-445$.

WICKENS, D. D., \& CLARK, S. Osgood dimensions as an encoding class in short-term memory. Journal of Experimental Psychology, 1968, 78, 580-584.

YOUNG, P. T. A study upon the recall of pleasant and unpleasant words. American Journal of Psychology, 1937, 49, 581-596. 